\title{
Does Energy Dependence Threaten the State Economy?
}

\author{
Eliška Straková1, Eva Kalinová ${ }^{2}$
}

\author{
${ }^{1}$ Institute of Technology and Business in České Budějovice, School of Expertness and \\ Valuation, Czech Republic \\ ${ }^{2}$ University of Žilina, Faculty of Operation and Economics of Transport and \\ Communications, Slovakia
}

\begin{abstract}
The combination of the need to adjust the energy mix in favor of the environment and the demands on energy consumption and at the same time on the economic growth of states leads to an increase in energy dependence. The high level of energy dependence is often cited as a potential threat to the economic growth of the state. The aim of the paper is to find out whether there is a correlation between macroeconomic indicators and the degree of energy dependence. Using the Pearson correlation coefficient, we examine the strength of the relationship between GDP, trade balance, inflation, unemployment and the degree of energy dependence on the example of the states of the European Union in the period 2005-2018. The results of the research show that the relationship between the degree of energy dependence and macroeconomic indicators for the European Union is completely individual and the strength and direction of correlation varies from country to country. Combining the degree of energy dependence in general with the direct threat to economic growth therefore proves to be misleading and it is necessary to always deal with a specific state in this matter and take into account other factors that could affect the relationship under study. These conclusions represent the beginning of a paradigm shift that energy dependence threatens the state economy, and therefore more emphasis can be placed on other aspects, such as the environmental ones, when adopting new energy strategies.
\end{abstract}

Keywords: energy dependence, GDP, inflation, balance of payments, unemployment, Pearson correlation coefficient, correlation, EU 


\section{Introduction}

In connection with the economic growth and industrial development of a country, there is often an increase in energy consumption. At the same time, all economic activity is directly dependent on the availability of energy, and its importance in the global economy is still growing. If a state is to sustain economic growth, it is essential to ensure a sufficient supply of energy (Binhack and Tichý, 2011). Due to the fact that a state covers energy consumption not only by its own resources but also by imports, it becomes energy dependent. The degree of energy dependence of each state changes over time depending on many factors, but in general its increase, which we can observe, is the cause of discussions at the national and supranational level.

In the case of the Member States of the European Union, not only is there a debate, but also an adjustment of strategies and the adoption of measures at the EU level, which is also responsible for handling energy (EUROPEAN COUNCIL, 2020). Currently, most EU countries deal with more than half of energy consumption through imports, and the ratio is still growing. Along with the increase in energy non self-sufficiency, there is also an issue of energy security, which the International Energy Agency (2020) defines as the continuous availability of affordable energy resources. From this it follows that if a state is energy dependent, it has no control over the external influences that determine energy imports, and thus its economy may be jeopardised.

In addition to endangering energy imports, diversification of energy sources is also an important aspect of energy security. It is well known that there are many ways to obtain energy. The most important fossil energy raw materials include oil, natural gas and coal. Other commonly used energy sources include nuclear, hydro, wind and solar (Hykl, 2015). Along with scientific and technological progress, preferences for the use of individual energy sources have changed in recent decades. Whether it is caused by technology that allows the use of a new energy source or new environmental knowledge that motivates the transition to other energy sources, or even the depletion of one energy source, so the transition to another energy source becomes a necessity for every country, the ratio of the structure of energy sources changes over time. However, this change may directly result in a decline in domestic energy production and there is a need to cover energy consumption with imports.

At present, the members of the European Union are required to meet the strategic energy targets in the form of a $20 \%$ transition to renewable energy sources, a $20 \%$ improvement in energy efficiency and a $20 \%$ reduction in greenhouse gas emissions (EUROPEAN COUNCIL, 2015). However, the requirements for a responsible approach to the environment are currently also coming from society as a whole towards businesses (Kasych, et al., 2020). This places demands on states to change the structure of energy sources at the national and supranational level, which, according to the above, has an impact on the degree of energy dependence. It is clear that if the members of the European Union are to be motivated to pursue these strategic goals, they should not be afraid of the impact on economic growth. As the main indicative value of economic growth is 
macroeconomic indicators, it is currently extremely beneficial to identify the relationship between these indicators and energy dependence. The aim of the paper is to find out whether there is a correlation between macroeconomic indicators, which are GDP, trade balance, inflation and unemployment, and the degree of energy dependence, in the Member States of the European Union in the period between 2005 and 2018. The examined sample consists of EU countries, regardless of whether they were members throughout the period under review or became members during the study period.

\section{Literature Research}

Karanfil and Li (2015) deal with the issue of the short-term and long-term relationship between economic growth and energy demand. By applying the panel data model, they confirmed the existence of a relationship between economic growth and energy consumption, the nature of which, however, is strongly influenced by regional differences. Factors determining energy consumption are the degree of electrification, urbanisation or the economic level of development of the state. This, using time series analysis, the Augmented Dickey-Fuller test (ADF test), the Kwiatkowski-Phillips-Schmidt-Shin test (KPSS test) and the Granger causality, is confirmed by Azam et al. (2016), Based on the example of Greece, who state that income, foreign direct investment and population growth directly determine Greece's energy consumption. Using the example of OECD countries, Damette and Seghir (2013) analyse the relationship between energy consumption and economic growth and come to the conclusion that this relationship is two-way. Not only does energy consumption in these countries increase economic growth in the short term, but in the long run, economic growth also increases energy consumption. Using the same method, Osman, Gachino and Hoque (2016) also had comparable results for the GCC countries, with a change in energy consumption policy that could have a negative impact on the economic growth of the GCC countries.

The two-way dependence of energy consumption and economic growth was confirmed by Dagher and Yacoubian (2012) using the Hsiao, Toda-Yamamoto and Granger causality tests in the case of Lebanon. They point to the negative aspect of this dependence in the sense that energy is the limit to the growth of the country's economy. As a reduction in energy consumption would negatively affect Lebanon's economic growth, they see energy dependency as a risk and emphasize the importance of domestic sources. Metcalf (2014) completely disagrees with this, stating that not reducing energy dependence, but reducing energy consumption is the way to ensure the energy security of a country, specifically the USA. He states that, for example, oil shocks will affect energy prices even if the country becomes energy self-sufficient. However, we can take such an attitude in the case of the USA, not Lebanon and the like, as these are completely different regions, where different levels of economic indicators and other regional differences may be the reason why each country limits other factors in terms of energy security.

Whether the level of vulnerability of the economy to energy shocks decreases with economic development has also been examined by Van de Ven and Fouquet (2017). They 
came to the conclusion that the vulnerability of the economy is not systematically dependent on economic growth, but depends on the circumstances associated with the demand and supply of energy resources. They stated that as the dependence on coal increases, the impact of energy shocks increases and that the distribution of dependence between coal and oil decreases the impact (Van de Ven and Fouquet, 2017). Czech (2017) examines the efforts to ensure energy security in the case of Poland. He sees the vulnerability of Poland's economy in terms of energy in its dependence on imports. It is considered that domestic coal resources are crucial for Polish energy security. However, due to environmental commitments to the EU, Poland is forced to move away from coal dependence, leading to an increase in energy dependence. The EU itself is tackling energy dependence. According to Fedoseeva and Zeidan (2018), the EU's economic growth is linked to the consumption of fossil fuels. As Russia is the primary importer of fossil fuels for the EU, EU's economic growth may be jeopardised.

However, in addition to economic growth, the issue of renewable resources resonates with the European Union's energy policy. Based on an econometric analysis, Acaravci and Erdogan (2018) came to the conclusion that economic growth affects emissions, while the use of renewable resources has no effect on emissions. They therefore recommend using renewables to resolve the conflict between reducing emissions and maintaining economic growth. Belaid and Zrelli (2019) share this view, confirming, using econometric models, that the growth of fossil fuels increases with economic growth and the volume of CO2 in the atmosphere increases with the consumption of fossil fuels. Renewables, on the other hand, have not shown a link to CO2 level growth. Svobodová et al. (2020) contribute to this issue through research that demonstrates a direct link between the size of countries' economies and $\mathrm{CO} 2$ production. It states that, although there are opportunities for the use of new energy technologies and capital investment, states still prefer to protect national economies and approach long-term environmental goals through marginal investment. The protectionist behaviour of countries is supported by Northrop, which states that in the light of the Paris Agreement goals, GDP growth requires growth in fossil fuel consumption, renewables are unable to meet energy consumption requirements and economic growth is therefore incompatible with reducing emissions (Northrop, 2017). However, using the method of modelling structural equations, Chien and $\mathrm{Hu}$ (2008) demonstrate that the use of renewable energy sources has a positive effect on GDP growth, although they admit that it has no effect on trade balance. The positive effect of renewables on GDP and on dependence on imports was demonstrated by Andini et al. (2019) on the example of Portugal by applying a vector autoregression model and using macroeconomic and energy data. For countries that use coal as their majority energy source, the transition to clean sources is complicated, even though they are aware of environmental issues and the need to change the energy mix (Dvorak et al., 2017).

In the question of the impact of renewables and GDP growth, Ohler and Fetters (2014) applied a panel data model extended by cross-sectional data and, using econometric analysis on the example of OECD countries, came to the conclusion that it depends on specific types of renewables and their combinations. They stated that, for example, the 
use of biomass, hydropower and wind in the long term has a positive effect on the GDP of OECD countries. The claim that it depends on the type of energy sources and their combination is confirmed by other authors. Within the European Union, Csereklyei et al. (2017) found that higher-income countries tend to achieve a better mix of energy sources and thus achieve better results in eliminating the dependence on fossil fuels. The best results are achieved by countries with a combination of nuclear energy and hydroelectric sources. Although they admit a low percentage of renewable resources, they conclude that the quality of the energy mix will increase as GDP grows.

The impact of a good choice of energy sources on macroeconomic indicators is reported by Bulavskaya and Reynes (2018) on the example of the Netherlands. Based on the analysis of the energy transition model, they predict GDP growth, the creation of a large number of jobs and an increase in investments. At the same time, the transition to the energy mix should lead to lower energy production, higher imports and higher energy prices. Punzi (2019) warns against the dependence of smaller states in particular on imports. Based on a dynamic stochastic general equilibrium model (DSGE), he explains that when a small economy is dependent on energy imports, it is exposed to energy price volatility. This causes long-term market uncertainty, business cycle volatility and economic slowdowns.

At the same time, the increase in energy imports, together with economic growth, is not uncommon in European countries. Using Granger's causality, Vecchione (2011) proves that even in Italy there is a causal link between GDP growth and decline and energy import growth and decline, and considers that such a high degree of energy dependence poses a risk to the Italian economy. The same relationship is described by Balaguer et al. (2015) in the case of Spain, adding that this dependence has been particularly evident since Spain's accession to the EU. Not only imports but also exports of energy sources can cause economic dependence. According to Tang et al. (2016) China's energy exports make such a significant contribution to economic growth that a change in energy policy is completely impossible in the near future. Whether a country is an energy importer or exporter, Jalil (2014) states, based on the use of the panel method, that energy consumption itself is essential for economic growth, not energy dependence.

The use of the Pearson correlation analysis is the best method to determine the existence of a relationship and its strength between macroeconomic indicators and the degree of energy dependence. The result will be a useful contribution to the ongoing debate on the ambiguous relationship between economic growth and energy dependence.

\section{Methodology}

As mentioned above, the main macroeconomic indicators include GDP, inflation, unemployment and the trade balance. In order to meet the aim of the paper, it is necessary to ask the following partial research questions:

- Is there a relationship between energy dependency and GDP growth? 
- Is there a relationship between energy dependency and inflation?

- Is there a relationship between the energy dependency rate and the unemployment rate?

- Is there a relationship between the unemployment rate and the trade balance?

We will analyse these relationships on the examples of 28 states that are or were members of the European Union. These are Austria, Belgium, Bulgaria, Croatia, Cyprus, the Czech Republic, Denmark, Estonia, Finland, France, Italy, Ireland, Lithuania, Latvia, Luxembourg, Hungary, Germany, the Netherlands, Malta, Poland, Portugal, Romania, Greece, Sweden, Spain, the Slovak Republic, Slovenia and the United Kingdom. We will work with annual data in the period from 2005 to 2018 incl.

Data for the degree of energy dependence will be obtained from the European Union database Eurostat under the term Energy dependence. The degree of energy dependence is defined here as net imports divided by gross available energy, with net imports calculated as total imports minus total exports and gross available energy calculated as primary production plus recovered and recycled products plus imports minus exports plus changes in inventories (Cepel et al., 2020). Data for macroeconomic indicators of countries is obtained from the World Bank (2020) database World Development Indicators. For GDP, defined as the sum of the gross value added of all resident producers in a state's economy plus taxes on products minus subsidies not included in the value of products, we choose the parameter GDP (current USD). The inflation rate, which is in the database as the parameter Inflation, consumer prices (annual \%), is measured by the consumer price index and indicates the annual percentage change in the average consumer's cost of purchasing a basket of goods and services. The unemployment rate expresses the number of people of working age who are unemployed as a percentage of the labour force. The data is listed in the database as Unemployment, total (\% of labour force) (modelled ILO estimate). Data for the trade balance, in the World Bank (2020) database kept under the name Net trade in goods and services (BoP, current USD), is calculated as the difference between the net imports and exports of a given country and foreign countries (EUROSTAT, 2020).

To calculate the relationship between macroeconomic indicators and the degree of energy dependence, we use Pearson's correlation coefficient. By calculating Pearson's correlation coefficient $\boldsymbol{r}$, we find out whether there is a correlation between the rate of energy dependence and GDP, the rate of inflation, the rate of unemployment and the trade balance, and how strong it is. If $r=0$, there is no linear correlation between the indicators. If $r<0$, there is a negative relationship, if $r>0$, the correlation is positive. The coefficient $r$ must be $<1$ and $>-1$. The formula for calculating the coefficient $r$ is as follows:

$$
r=\frac{\sum_{i}\left(x_{i}-\bar{x}\right)\left(y_{i}-\bar{y}\right)}{\sqrt{\sum_{i}\left(x_{i}-\bar{x}\right)^{2}} \sqrt{\sum_{i}\left(y_{i}-\bar{y}\right)^{2}}}
$$


All data will be processed in Excel and we will use the Correl function to calculate the correlation coefficient $r$. To interpret the strength of correlation, we divide the coefficient $r$ into three groups according to its value into weak, medium and strong correlation. In this case, we will consider it a weak correlation if the value of $r$ is from 0.001 to 0.3 and from -0.001 to -0.3 . We determine the medium correlation for the value of $r$ from 0.3 to 0.5 and from -0.3 to -0.5 . We will consider the value of $r$ from 0.5 to 1 and from -0.5 to -1 as a strong correlation.

\section{Results}

As illustrated by Graph 1, the correlation between energy dependence and GDP is weakly positive in the case of Croatia, Hungary, Spain and the United Kingdom. Weak negative correlations occur in Belgium, Finland, Greece, Malta, the Netherlands, Portugal, Slovakia and Slovenia. A medium positive correlation is recorded in the Czech Republic, Germany and Lithuania. Medium negative correlations apply to Austria, Cyprus, France, Latvia and Romania. There is a strong positive correlation in Denmark and Poland. For Bulgaria, Estonia, Ireland, Luxembourg and Sweden, the correlation coefficient $r$ acquires a strong negative value.

Graph 1: Energy dependence and GDP (current USD)

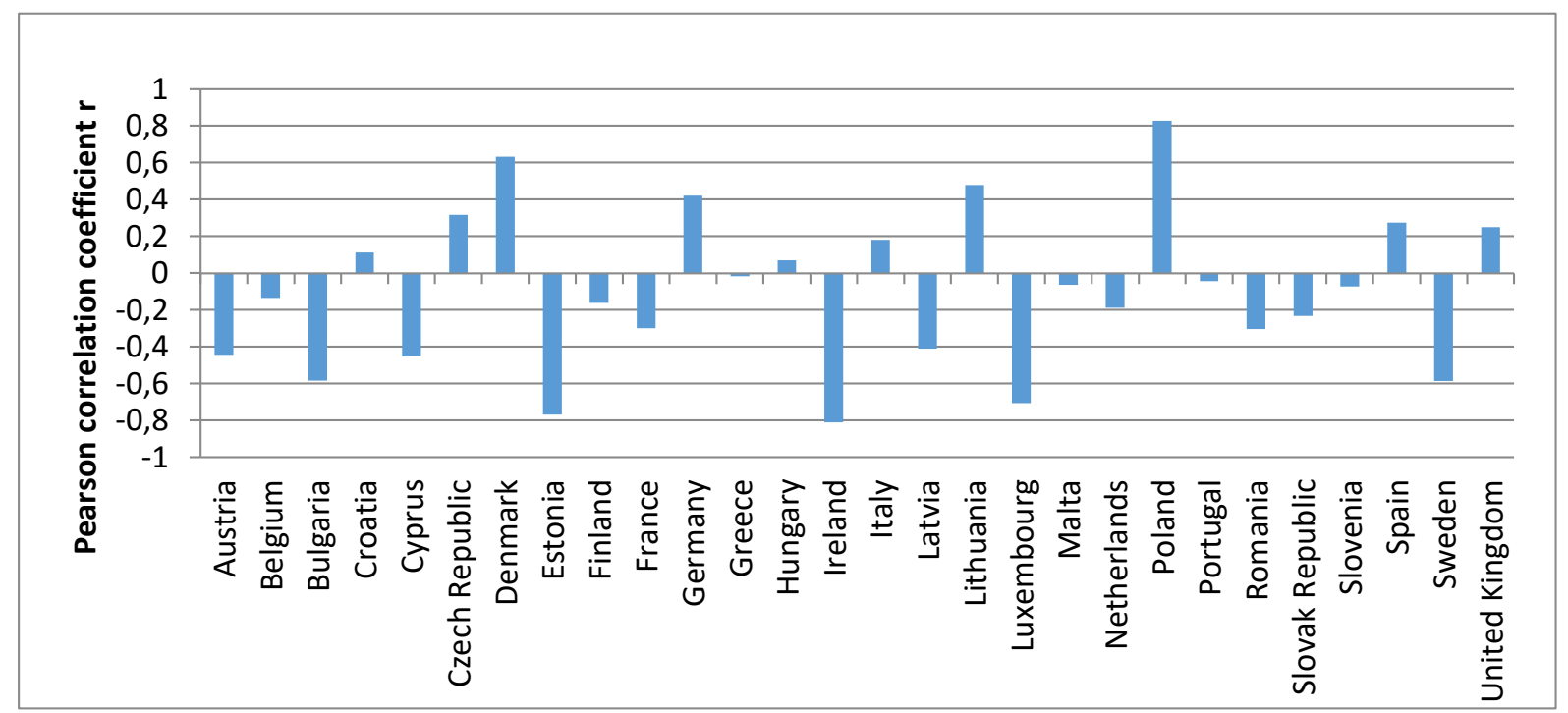

Source: Authors.

The correlation between energy dependence and inflation, as shown in Graph 2, is weakly positive for Cyprus, Greece, Hungary, Ireland, Malta, Poland and Sweden. A weak negative correlation occurs in Belgium, the Czech Republic and the United Kingdom. Medium positive correlations apply to Austria, Estonia, Finland and France. A medium negative correlation is demonstrated in Germany and the Netherlands. There is a strong positive correlation in Bulgaria, Croatia, Italy, Latvia, Portugal, Romania, Slovakia, Slovenia and Spain. A strong negative correlation occurs in Denmark and Lithuania. Here is Graph 2. 
Graph 2: Energy dependence and inflation (annual \%)

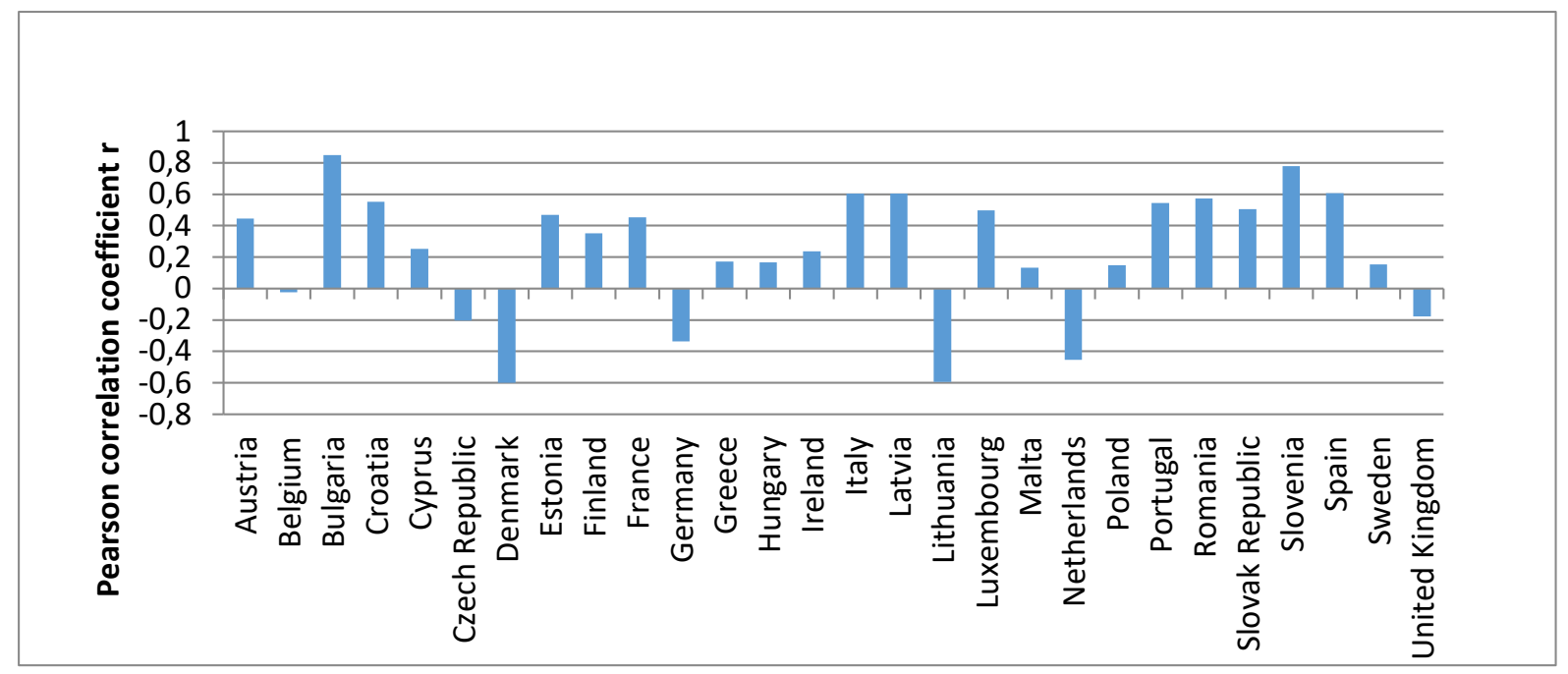

Source: Authors.

There is only a weak positive correlation between energy dependency and unemployment rates in Belgium, Estonia, Ireland, Malta and Sweden. A weak negative correlation occurs in Latvia, the Netherlands, Romania and Slovakia. A medium positive correlation exists in Denmark, Lithuania and the United Kingdom. Medium negative correlations apply to Austria, Bulgaria, Cyprus, Finland and Greece. A strong negative correlation occurs in Croatia, the Czech Republic, France, Germany, Hungary, Italy, Luxembourg, Poland, Portugal, Slovenia and Spain. Shown in Graph 3, there is no strong positive correlation between the level of energy dependence and unemployment in any of the monitored countries.

Graph 3: Energy dependence and unemployment (total \% of labour force)

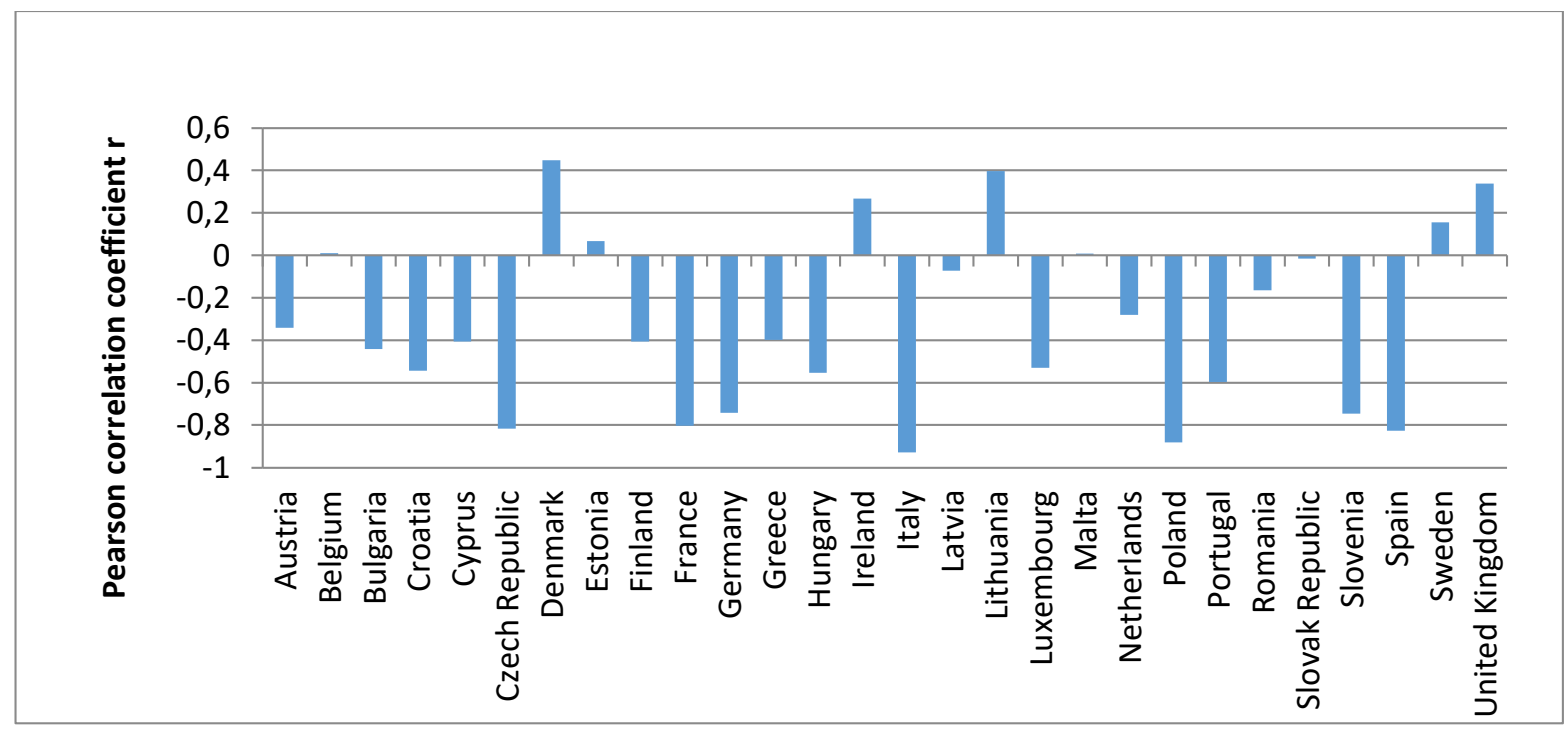

Source: Authors. 
The correlation between the degree of energy dependence and the trade balance is weakly positive for Austria, Belgium, France and the Netherlands. The correlation is weakly negative for Cyprus, Greece and Luxembourg. A medium positive correlation exists only for Germany. A medium negative correlation exists for Croatia and Poland. A strong positive correlation occurs in the Czech Republic, Denmark, Finland, Lithuania, Sweden and the United Kingdom. Bulgaria, Estonia, Hungary, Ireland, Italy, Latvia, Luxembourg, Portugal, Romania, Slovakia, Slovenia and Spain show a strong negative correlation. The processed data is listed in the appendix. The correlation between the degree of energy dependence and the trade balance is shown in Figure 4. All processed data are given in Appendix 1.

Graph 4: Energy dependence and net trade in goods and services (BoP, current USD)

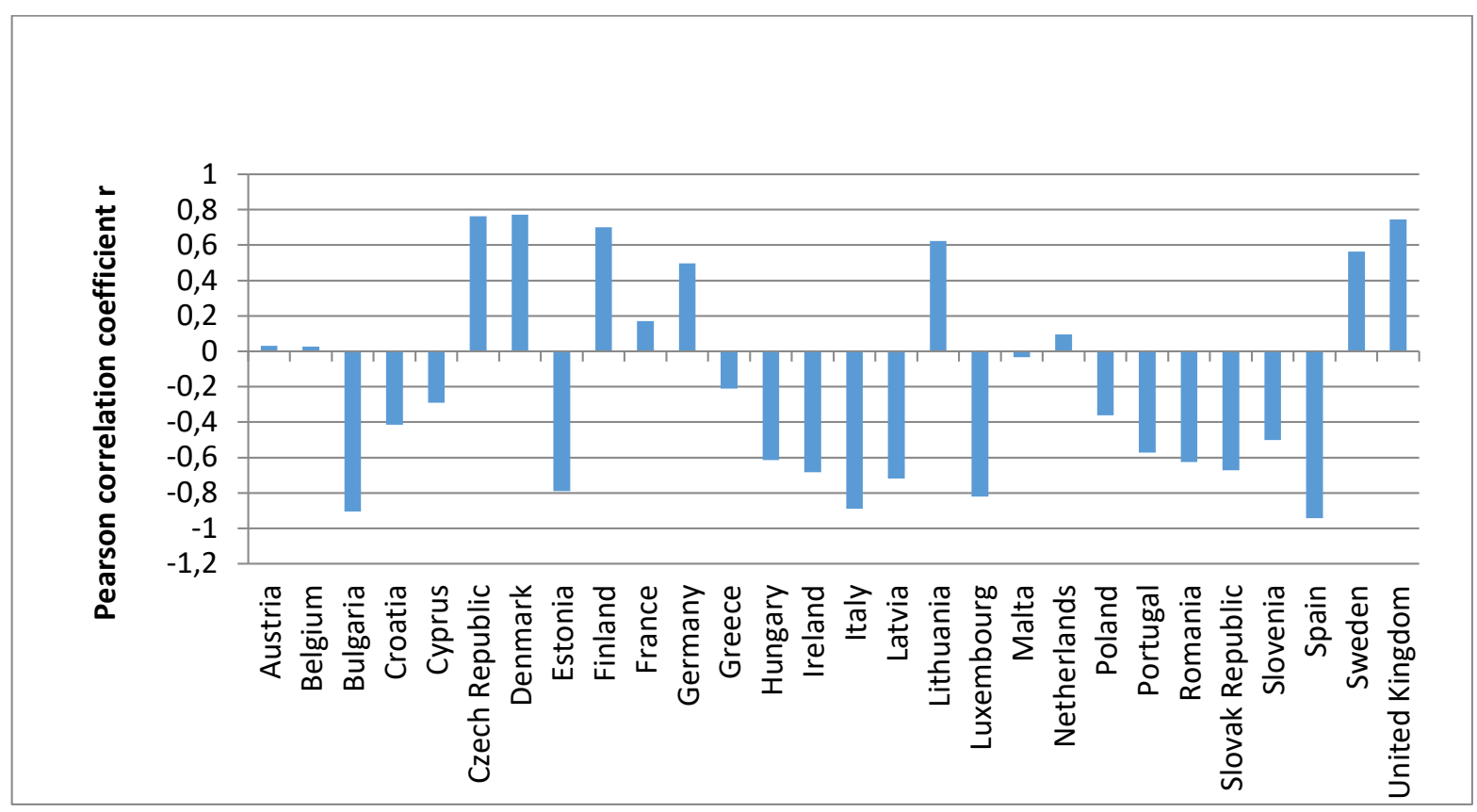

Source: Authors.

\section{Discussion}

Based on the obtained results, we are able to answer research questions that were determined previously:

Is there a relationship between the degree of energy dependence and GDP? The strength of the correlation is different in the case of the degree of energy dependence and GDP for each of the examined countries. In general, however, we can observe a trend that shows that there are fewer countries with a strong correlation than countries with a weak correlation. Specifically, 13 of the 28 states are weakly correlated in this case. Using the Pearson correlation coefficient, we found that only in case of 5 examined countries (Bulgaria, Estonia, Ireland, Luxembourg, Sweden) there is a strong negative correlation, i. e. the GDP growth decreases with the growth of the energy dependence rate. 
Is there a relationship between energy dependency and inflation? Interestingly, in this point of view, most, specifically 21 of the 28 countries surveyed, show a positive correlation of different strength level. At the same time, only 11 of the 28 countries surveyed show a strong correlation.

Is there a relationship between energy dependency and unemployment? There is a strong correlation between these indicators in only 11 cases. In addition, all these cases show a negative correlation. The relationship between energy dependency and unemployment rates did not prove strongly positive in any of the countries. Positive, medium or low degree correlations apply only to 8 out of 28 countries.

Finally, is there a relationship between the degree of energy dependence and the trade balance? Regarding the relationship between these indicators, we can say that of all four examined macroeconomic indicators, there is the highest number of countries with a strong correlation. Specifically, in 18 of the 28 countries surveyed we see a strong relationship between the degree of energy dependence and the trade balance, with 12 of these countries showing a strong negative correlation. In the case of 7 states, the correlation is weak.

It is therefore evident that in order to be able to answer research questions, it is first necessary to look at the states of the European Union individually. Using Pearson's correlation coefficient, we were able to answer these questions for each individual state studied. The results of the research clearly show that the relationship between the degree of energy dependence and macroeconomic indicators for the European Union is completely individual and its strength and direction vary from country to country.

Karanfil and Li (2015) come to a similar conclusion in the case of the relationship between GDP growth and decline and energy consumption growth and decline, who state that this is strongly influenced regionally. With regard to energy issues, Northrop (2017) supports the protectionist behavior of states concerned about economic growth. However, if we look at the relationship between the level of energy dependence and the GDP of the EU countries, we find that there are fewer countries in which have shown a strong correlation than countries in which we have proven a weak correlation. Similarly, Punzi (2019) warns smaller states against energy dependence due to possible negative economic impacts. However, some of the smaller countries surveyed, such as Malta and Cyprus, show a weak correlation for all or most macroeconomic indicators. In contrast, Luxembourg has a strong correlation with three out of four macroeconomic indicators. While Vecchione (2011) uses Granger causality to prove that there is a relationship between GDP growth and an increase in energy imports in the case of Italy, our research shows that the correlation between energy dependence and Italy's GDP is among the weakest in the EU. However, a strong correlation was demonstrated in Italy for other macroeconomic indicators.

A number of authors, Dagher and Yacoubian (2012), Czech (2017) and Fedoseeva and Zeidan (2018) discuss the energy dependence of the state as a potential threat to the state and its economies. However, based on the Pearson coefficient, the relationship between 
the degree of energy dependence and macroeconomic indicators is significant only in some countries, and the results show negative and positive correlations, so, after a closer examination, this relation could be a potential threat as well as an opportunity. Anyone who will continue to deal with the relationship between the degree of energy dependence and the economy of the state should take into account the results of this research and then identify the factors causing a strong relationship between these indicators. These conclusions represent the beginning of a paradigm shift that energy dependence threatens the state's economy, and therefore more emphasis can be placed on other aspects, such as the environmental ones, when adopting new energy strategies.

\section{Conclusion}

The aim of the paper was to determine whether there is a correlation between macroeconomic indicators, such as GDP, trade balance, inflation and unemployment, and the degree of energy dependence in the Member States of the European Union in the period between 2005 and 2018. Using Pearson's correlation coefficient, the strength of the relationship between the degree of energy dependence and the individual macroeconomic indicators for each country was studied, and the aim of the paper was thus achieved.

However, the strength and direction of the correlation is not the same for all countries surveyed or for all macroeconomic indicators for individual countries. In general, we can state that in the case of the relationship between the degree of energy dependence and GDP, weak correlation slightly prevails, in the case of the relationship between the degree of energy dependence and the trade balance, on the contrary, a strong correlation slightly prevails. The correlation between the rate of energy dependence and inflation reaches mostly positive values, while the correlation between the rate of energy dependence and unemployment is dominated by negative values. It is the fact that the results are not the same or show no trend in all the countries studied, which is the limit of the research result. It is not possible at this stage of research to reach a general statement, which could lead to a general recommendation.

The results shown above inevitably lead to the question, what is the cause of the individual nature of the relationship between the given parameters? How is it possible that the relationship under review does not show the same values in all countries? And what conditions precede the parameters of the investigated relationships? Based on the data we have collected for this research, it is not possible to answer these questions. Therefore, it is important to carry out further, follow-up research that answers the questions and identifies unknown variables that will help to understand the relationships between macroeconomic indicators and energy dependency, and thus be a useful support for energy decision-making with economic development. 


\section{References}

ACARAVCI, A. and S. ERDOGAN, 2018. Renewable energy, environment and economic growth nexus: An empirical analyses for selected countries. Eskisehir Osmangazi University Journal of Economics and Administrative Sciences, 13(1), p. 53-64.

ANDINI, C., R. CABRAL and J. E. SANTOS, 2019. The macroeconomic impact of renewable electricity power generation projects. Renewable Energy, 131, p. 1047-1059.

AZAM, M. et al., 2016. Socio-economic determinants of energy consumption: An empirical survey for Greece. Renewable and Sustainable Energy Reviews, 57, p. 1556-1567.

BALAGUER, J., T. FLORICA and J. RIPOLLES, 2015. Foreign trade and economic growth in Spain (1900-2012): The role of energy imports. Economia Politica, 32(3), p. 539-375.

BELAID, F. and M. H. ZRELLI, 2019. Renewable and non-renewable electricity consumption, environmental degradation and economic development: Evidence from Mediterranean countries. Energy Policy, 133(110929).

BINHACK, P. and L. TICHÝ, 2011. Energetická bezpečnost ČR a budoucnost energetické politiky EU [Energy security of the Czech Republic and the future of EU energy policy]

BULAVSKAYA, T. and F. REYNES, 2018. Job creationand economic impact of renewable energy in Netherlands. Renewable Energy, 113, p. 528-538.

CEPEL, M. et al., 2020. Business environment quality model in the SME segment. Transformations in Business\&Economics, 19(1), p. 262-283.

CHIEN, T. and J. L. HU, 2008. Renewable energy: An efficient mechanism to improve GDP. Energy Policy, 36(8), p. 3045-3052.

CSEREKLYEI, Z. et al., 2017. Energy paths in the European Union: A model-based clustering approach. Energy Economics, 65, p. 442-457.

CZECH, A., 2017. Economic dimension of Polish energy security. Oeconomia Copernicana, 8(3), p. 383-399.

DAGHER, L. and T. YACOUBIAN, 2012. The casual relationship between energy consumption and economic growth in Lebanon. Energy Policy, 50, p. 795-801.

DAMETTE, O. and M. SEGHIR, 2013. Energy as a driver of growth in oil exporting countries. Energy Economics, 37, p. 193-199.

DVORAK, J. et al., 2017. Updated energy policy of the Czech Republic may result in instability of the electricity grid in Central Europe. Clean Technologies and Environmental Policy, 20(1), p. 41-52.

EVROPSKÁ RADA [EUROPEAN COUNCIL], 2015. Online, available from https://www.consilium.europa.eu/en/policies/climate-change/

EVROPSKÁ RADA [EUROPEAN COUNCIL], 2020. Online, available from https://www.consilium.europa.eu/cs/policies/energy-union/ 
EUROSTAT, $2020 . \quad$ Online, available from https://ec.europa.eu/eurostat/databrowser/view/t2020_rd320/default/table?lang=en FEDOSEEVA, S. and R. ZEIDAN, 2018. How (a)symetric is the response of import demand to changes in its determinants? Evidence from European energy import. Energy Economics, 69, p. 379-394.

HYKL, A, 2015. V4+. Energy union and energy security. Association for International Affairs (AMO) for 21st season of Prague Student Summit, p. 3-10.

JALIL, A., 2014. Energy-growth conundrum in energy exporting and importing countries: Evidence from heterogeneous panel methods robust to cross-sectional dependence. Energy Economics, 44, p. 314-324.

KARANFIL, F. and Y. J. LI, 2015. Electricity consumption and economic growth: exploring panel-specific differences. Energy Policy, 82, p. 264-277.

KASYCH, A., P. SULER and Z. ROWLAND, 2020. Corporate environmental responsibility through the prism of strategic management. Sustainability, 12(22).

NORTHROP, E., 2017. A stable climate or economic growth? Review of Social Economy, 75(4), p. 510-552.

METCALF, G., 2014. The economics of energy security. Annual review of Resource Economics Research, 6(1), p. 155-174.

MEZINÁRODNÍ ENERGETICKÁ AGENTURA [INTERNATIONAL ENERGY AGENCY], 2020. Online, available from https://www.iea.org/areas-of-work/ensuring-energy-security

OHLER, A. and I. FETTERS, 2014. The casual relationship between renewable electricity generation and GDP growth: A study of energy sources. Energy Economics, 43, p. 125-139.

OSMAN, M., G. GACHINO and A. HOQUE, 2016. Electricity consumption and economic growth in the GCC countries: Panel data analysis. Energy Policy, 98, p. 318-327.

PUNZI, M., T., 2019. The impact of energy price uncertainty on macroeconomic variables. Energy Policy, 126, p. 1306-1319.

SVOBODOVA, K. et al., 2020. Complexities and contradictions in the global energy transition: A re-evolution of country-level factors and dependencies. Applied Energy, 265(114778).

TANG, X. et al., 2016. Nexus between energy consumption and economic growth in China: from the perspective. Emerging Markets Finance and Trade, 52(6), p. 1298-1304.

VAN DE VEN, D. and J. R. FOUQUET, 2017. Historical energy price shocks and their changing effects on the economy. Energy Economics, 62, p. 204-216.

VECCHIONE, G., 2011. Economic growth, electricity consumption and foreign dependence in Italy between 1963-2007. Energy Sources part B-Economics Planning and Policy, 6(3), p. 304-313. 
DOI: https://doi.org/10.36708/Littera_Scripta2020/2/2

WORLD BANK, 2020. Online, available from (https://databank.worldbank.org/indicator/NY.GDP.MKTP.CD/1ff4a498/PopularIndicators\#)

\section{Contact address of the authors:}

Mgr. Eliška Straková, Institute of Technology and Business in České Budějovice, School of Expertness and Valuation, Okružní 517/10, 37001 České Budějovice, Czech Republic, email: strakovae@mail.vstecb.cz

Ing. Eva Kalinová, University of Žilina, Faculty of Operation and Economics of Transport and Communications, Univerzitná 8215/1, 01026 Žilina, Slovakia, e-mail: kalinova@mail.vstecb.cz 